2002s-68

Multi-item Auctions for Automatic Negotiation

\author{
Houssein Ben-Ameur, Brahim Chaib-draa \\ and Peter Kropf
}

\begin{tabular}{c}
\hline Série Scientifique \\
Scientific Series
\end{tabular}

Montréal

Juillet 2002

(C) 2002 Houssein Ben-Ameur, Brahim Chaib-draa, Peter Kropf. Tous droits réservés. All rights reserved. Reproduction partielle permise avec citation du document source, incluant la notice (C)

Short sections may be quoted without explicit permission, if full credit, including $@$ notice, is given to the source.
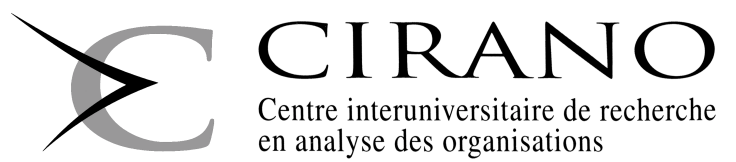

Centre interuniversitaire de recherche en analyse des organisations 


\section{CIRANO}

Le CIRANO est un organisme sans but lucratif constitué en vertu de la Loi des compagnies du Québec. Le financement de son infrastructure et de ses activités de recherche provient des cotisations de ses organisationsmembres, d'une subvention d'infrastructure du ministère de la Recherche, de la Science et de la Technologie, de même que des subventions et mandats obtenus par ses équipes de recherche.

CIRANO is a private non-profit organization incorporated under the Québec Companies Act. Its infrastructure and research activities are funded through fees paid by member organizations, an infrastructure grant from the Ministère de la Recherche, de la Science et de la Technologie, and grants and research mandates obtained by its research teams.

\section{Les organisations-partenaires / The Partner Organizations}

-École des Hautes Études Commerciales

-École Polytechnique de Montréal

-Université Concordia

-Université de Montréal

-Université du Québec à Montréal

-Université Laval

-Université McGill

-Ministère des Finances du Québec

-MRST

-Alcan inc.

- AXA Canada

-Banque du Canada

-Banque Laurentienne du Canada

- Banque Nationale du Canada

- Banque Royale du Canada

-Bell Canada

-Bombardier

-Bourse de Montréal

-Développement des ressources humaines Canada (DRHC)

-Fédération des caisses Desjardins du Québec

-Hydro-Québec

-Industrie Canada

-Pratt \& Whitney Canada Inc.

-Raymond Chabot Grant Thornton

-Ville de Montréal

Les cahiers de la série scientifique (CS) visent à rendre accessibles des résultats de recherche effectuée au CIRANO afin de susciter échanges et commentaires. Ces cahiers sont écrits dans le style des publications scientifiques. Les idées et les opinions émises sont sous l'unique responsabilité des auteurs et ne représentent pas nécessairement les positions du CIRANO ou de ses partenaires.

This paper presents research carried out at CIRANO and aims at encouraging discussion and comment.

The observations and viewpoints expressed are the sole responsibility of the authors. They do not necessarily represent positions of CIRANO or its partners.

\section{ISSN 1198-8177}




\title{
Multi-item Auctions for Automatic Negotiation
}

\author{
Houssein Ben-Ameur ${ }^{\dagger}$, Brahim Chaib-draa ${ }^{*}$ amd Peter Kropf ${ }^{*}$
}

\section{Résumé / Abstract}

Dans un environnement multiagent, les ressources peuvent toujours s'avérer insuffisantes relativement à un nombre élevé de demandes. Dans ce cahier, nous proposons une approche mixant les enchères et les agents logiciels en vue de contribuer à résoudre ce problème. Cette approche consiste en fait à utiliser le mécanisme d'enchères multi-articles en vue d'allouer les ressources à un ensemble d'agents. À cet effet, nous considérons le problème de ressources comme un marché dans lequel évoluent des agents acheteurs et des agents vendeurs négociant des articles représentant des ressources. Ces agents utilisent des enchères multi-articles et par conséquent ils constituent un processus de négociation automatisé et programmé comme un réseau d'agents logiciels. Dans ce type de négociation, chaque agent exhibe différentes capacités d'acquisition lui permettant ainsi d'agir différemment selon le contexte ou la situation de marché. Par exemple, plus on est riche, plus on peut acheter d'articles. Nous présentons pour ce modèle une enchère anglaise et nous discuterons ses résultats expérimentaux.

Available resources can often be limited with regard to the number of demands. In this paper we propose an approach for solving this problem which consists of using the mechanisms of multiitem auctions for allocating the resources to a set of software agents. We consider the resource problem as a market in which there are vendor agents and buyer agents trading on items representing the resources. These agents use multi-item auctions which are viewed here as a process of automatic negotiation, and implemented as a network of intelligent software agents. In this negotiation, agents exhibit different acquisition capabilities which let them act differently depending on the current context or situation of the market. For example, the "richer" an agent is, the more items it can buy, i.e. the more resources it can acquire. We present a model for this approach based on the English auction, then we discuss experimental evidence of such a model.

Mots clés : Systèmes multiagents, négociations, enchères multi items.

Keywords: Multi-agent systems, Negotiations, Multi-item auctions.

\footnotetext{
† CIRANO, 2020 University Ave, 25th floor, Montréal QC, H3A 2A5 CANADA, email: Houssein.Benameur@cirano.qc.ca.

* Brahim Chaib-draa is Professor, Department of Computer science and Software-Engineering, Université Laval, Ste-Foy, PQ, Canada; and CIRANO, 2020 University Ave, 25th floor, Montréal QC, H3A 2A5 CANADA; email: chaib@ift.ulaval.ca.

† Département d'Informatique et de Recherche Opérationnelle, Université de Montréal, Montréal, Canada and CIRANO, 2020

University Ave, 25th floor, Montréal QC, H3A 2A5 CANADA; email: kropf@iro.umontreal.ca.
} 


\section{Introduction}

\subsection{Agent and Multi-agent Systems}

The steadily increasing interconnection of devices raises many research issues with regards to the ways in which all these distributed machines can interact effectively with other humans or machines. Artificial intelligence and software engineering have a role to play in how the computers can interact in a "rational" way. Several groups of researchers propose autonomous agents for addressing this big issue. Autonomous agents are software systems that are capable to independently act on open, unpredictable environments. They are considered as a new paradigm for developing software applications involving artificial intelligence techniques and distributed computing.

Indeed, agent technology is a significant area of interest for such applications as telecommunications, information management, Internet search engines, electronic commerce, computer games, interactive cinema, information retrieval and filtering, user interface design, industrial process control, planning and logistics, etc. The successful adoption of this technology in all these areas will have a profound impact both on industry, and also on the way in which future computer systems will be conceptualized and implemented.

At present, there is much debate about what agent-hood is exactly, and there is nothing approaching a consensus as it is generally the case for any new field. However, an increasing number of researchers define agents as being:

1. situated or embedded in a particular environment;

2. designed to fulfil specific roles;

3. clearly identifiable entities with well-defined (and limited) resources and interfaces;

4. autonomous in the sense that they have control over their behavior;

5. capable of exhibiting flexible behavior which can be reactive, proactive, sociable or persistent.

In the context of concurrent and distributed systems, it becomes obvious that a single agent is insufficient. Many applications, if not most of them, require multiple agents, called also multi-agent systems (MAS). In such systems, knowledge, action and control are distributed among the agents, which may cooperate, compete or coexist depending on the context in which they operate. According to Weiss [1], there are two main reasons which drive forces behind the growth of the MAS paradigm in recent years.

The first is that multi-agent systems have the capacity to play a key role in current and future computer science and its application. Modern computing platforms and information environments are distributed, large, open, and heterogenous. Computers are no longer stand-alone systems, but have become closely connected both with each other and their users. The increasing complexity of applications often lead to the design of "individual" software agents instead of a large entity which is in general less 
flexible. The technology that MAS promises to provide, are among those that are urgently needed for the Internet, telecommunications, TV-web, e-commerce, e-business, etc.

The second reason is that multi-agent systems have the capacity to play an important role in developing and analyzing models and theories of interactivity in human societies.

These two reasons combined show the relevance of MAS for understanding, implementing and operating complex socio-technical systems as represented by e-business systems.

In this paper we propose a model for multi-item auctions which has a strong relationship to the efforts in building multi-agent systems. We start from the interactivity between humans in a market, specially for the multi-item sell/buy negotiations, and we try to realize it under the form of a negotiation between software agents.

\subsection{Auctions: From Economy to the Automatic Negotiation}

Auctions are a market mechanism already introduced in the ancient world. Traditionally, they allow selling rare and unusual goods, and apply in situations where a more conventional "market", in which buyers consider the price as given, do not exist. A large informal body of knowledge on auctions has been in existence for centuries, and a more formal, game theoretic analysis of auctions began in the 1960's with the pioneering work of Vickery [2]. The field of micro-economics and game theory that studies these and related issues is often called 'mechanism design' or 'implementation theory'. An introduction to this field can be found in the text books [3, 4].

With the widespread availability of the Internet and e-commerce technologies, economists have started to consider auctions as an important economic model. Indeed, the theory of auctions exhibits many interesting features at the practical, empirical and theoretical level. Paul Klemperer [5] gives three reasons why the theory of auctions is relevant to economists:

1. A growing number of large volume transactions are realized through auctions. Examples include the many auctions organised by governments [6], the enterprise wide electronic procurement systems for all sorts of goods, or the electronic auction markets such as EBay [7, 8].

2. Auctions offer relatively simple mechanisms in a well defined economic environment. They offer thus to economists a vast field for experimental research allowing to obtain empirical results that can be suitably validated.

3. The theory of auctions has already revealed many scientific results in economy, which have allowed to develop new methods for pricing in competitive markets. Moreover, it has also helped to further understand complex negotiation mechanisms between vendors and buyers.

Recently, we have noted a great rise in the popularity of auctions of various types [9]. This development occurred in many settings: in government privatizations and rights allocation (most famous is the FCC spectrum right auctions [6]) [10, 11]; in the many 
Internet auction sites [7, 8]; in the usage of techniques from auction theory for computational resource allocation [12]; in computerized agent systems [13, 14]; and current trends in B2B e-commerce [15].

Besides the research on auction mechanisms undertaken in economics and operations research, the technology necessary to implement electronic auctions $[16,17,18]$ is a research issue on its own. Agent technology has already been applied in different work $[19,20,21,22]$. This paper concentrates on the approach of applying on agent technology in e-commerce.

The application of the multi-agent paradigm to auctions can be viewed from two different points of view:

1. The mechanisms of an auction can be defined as a resource allocation problem to a set of agents. The available resources are limited with regard to the number of demands. The problem may thus be described as a market in which there are vendor agents and buyer agents which trade on items represented by the resources. These agents exhibit different acquisition capabilities which let them act differently depending on the current context or situation of the market. For example, the "richer" an agent is, the more items it can buy, i.e. the more resources it can acquire.

2. The auctions can be viewed as a process of automatic negotiation implemented as a network of intelligent agents. Buyer and vendor agents interact in an electronic market environment to trade items. Such an approach is for example represented by AuctionBot [23]. Alternatively, auctions may form an integral part of a multi-agent architecture. An example of this approach is represented by the NetSA architecture [24]. In this architecture, supervisor agents associated with institutions offer a same product in competition with each other applying auction mechanisms in order to offer to a user agent the best price for the product.

The work presented in this paper focuses on the second approach where auctions are considered as a process of automatic negotiation applying the multi-agent paradigm. In the next section, we explain how we see auctions for automatic negotiation between agents. Section 3 presents a model for multi-item auctions. The strategy and equilibrium conditions of the auction process relying on this model are presented and analyzed in Section 4. The following section presents an implementation of the model. The simulation results of three typical cases are presented and discussed in Section 6. Finally, we conclude the paper in Section 7.

\section{Auctions for automatic negotiation}

\subsection{Market framework}

An environment where vendors and buyers meet with the goal to sell and buy goods is commonly called a market. As there are many different interpretations of what a market is, such an environment should rather be called a market framework. Figure 1 shows an example of such a framework [25, 26, 27]. There are four cases presented: 
1. One vendor and one buyer directly negotiate in the classical sense;

2. Multiple vendors and one buyer are engaged in a reverse auction;

3. Multiple buyers and one vendor are engaged in a classical auction (English, Dutch, Vickery, etc.);

4. Multiple buyers and vendors trade in a market.

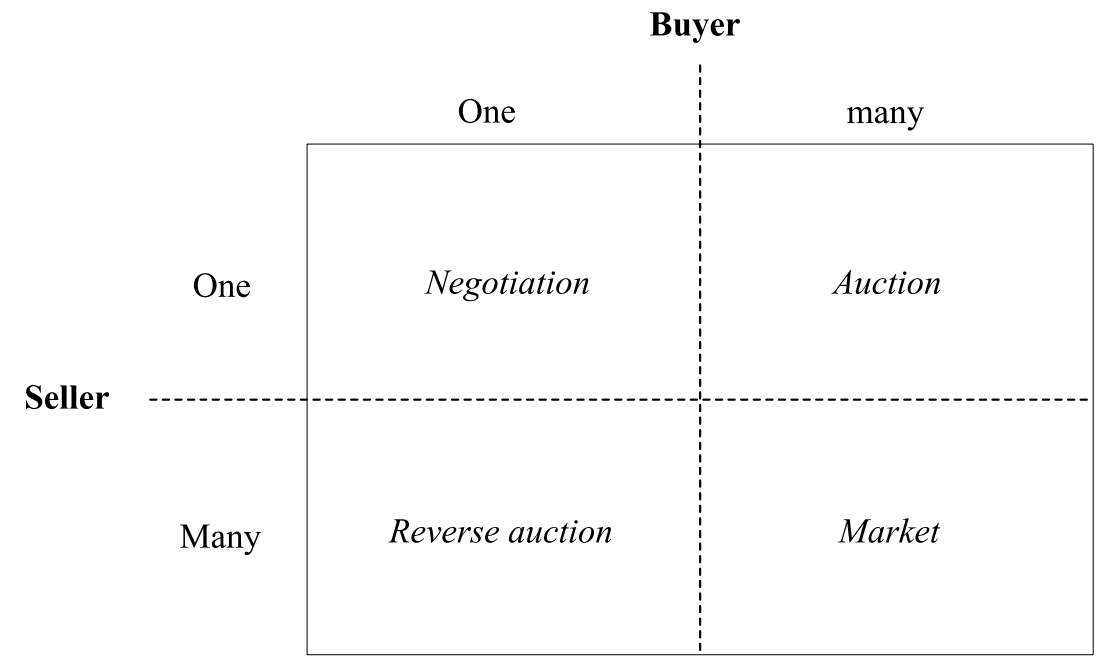

Figure 1: A market framework example.

The distinction between negotiations, auctions and markets is, however, not so strict. This rough classification leaves therefor room for variations such as combined negotiations [28], synchronous open auctions, and combinatorial auctions. Moreover, combinations are also possible: one can imagine a model where auctions are used as a mechanism for automatic negotiation in electronic markets. In the following, a model for this combination applying the multi-agent paradigm is presented.

\subsection{Auctions and automatic negotiation}

Economic models have been adopted in various work on the problem of negotiation and resource allocation in multi-agent systems. Ferguson [29] justifies this choice by the availability of the many mathematical tools related to numerical economics. Evidently, these tools are of great value when resolving the resource allocation problem in complex information systems.

Negotiation is central to any commerce and market. It can be defined as "Mechanism that allows a recursive interaction between a principal and a respondent in the resolution of a good deal" [30].

In [13], S. Rosenchein and G. Zlotkin propose five attributes that are necessary for a 'good' negotiation mechanism: efficiency, stability, simplicity, distributivity and 
symmetry. These characteristics can all be found when considering an auction model for automatic negotiation:

Efficiency. To show the efficiency of an auction is often very difficult, if not impossible to undertake without imposing severe restrictions such as independent private evaluations, risk neutrality, homogeneous buyers, independent products to sell, etc. However, these restrictions are quite straightforward to implement in a multi-agent system. Indeed, the agents are often considered as rational entities seeking to maximize a well defined utility function based on precise rules. By imposing on an architecture strict social relations between the different buyers, a simple auction model can be designed, which follows the simplifying restrictions. This will assure the efficiency of the proposed auction mechanism.

Stability. An obvious method to achieve stability is to forbid an agent to cancel or reconsider offers once they have been submitted.

Simplicity. Auction mechanisms are in general quite simple to implement. This is in fact one of their strength. Considering the number of messages to communicate, the only communications necessary are the offers and the responses of the vendor.

Distributivity. At first sight, distributivity is only partially fulfilled: while there are multiple (independent) buyers, the vendor or auctioneer is a central entity. However, in a more complex environment, i.e. a market, different buyers and vendors may negotiate. In such an environment there is no global central entity anymore. The vendors may either act independently or coordinate their activities. This allows for multiple simultaneous auctions.

Symmetry. The symmetry is easily achieved by assuring that all participating agents have access in the same way to all information available to them. No agent will thus be privileged with regard to others.

There are other characteristics of auctions supporting the application of auction mechanisms for automatic negotiation. An auction restricts the negotiation variables essentially to the price and the quantity in case of multiple items. Moreover, an open auction allows the agent to review his offers, and if the auction is public, to refine them by analyzing the offers of other participants and by considering the auction's evolution. The negotiation strategy may thus be adapted according to the rules of the market. Finally, an auction negotiates a mutually acceptable solution for both the vendor and the buyer while the market forces alone decide on the negotiation termination. The use of auctions as a mechanism for automatic negotiation and for resource re-allocation in multi-agent systems was demonstrated by T. Sandholm [31, 32].

The previous discussion shows that auctions are appropriate for automatic negotiations. Auctions may also be applied to efficiently design a market framework. However, some differences between negotiations and auctions with regard to electronic commerce applications can be identified [20]. The participants of an electronic auction cannot make mutual concessions or agreements. Such an auction is thus not considered as a mechanism for negotiation. This is however only true, if the negotiation is 
restricted to only one dimension, i.e. the current price of the item in the auction. If more dimensions such as quantity and quality are considered [33], auctions may be considered as negotiation mechanisms where the buyers might make concessions on one or the other dimension in order to favor one specific dimension. Dually, the vendor might operate on the different dimensions and dynamically adjust the selling strategy in the auction. The multi-item auction model presented in the next section is based on these considerations.

\section{A Multi-item auction model}

We are interested in auctions that include multiple identical items. Most work on multiitem auctions suppose two simplifying conditions: the quantity of items to sell is fixed as well as the quantities requested by the buyers. These two hypothesis do not meet the requirements of many situations where auctions are used. Lengweiler [34] for example proposes an auction model, where the available quantity is not fixed. It can therefore change during the auction as it is for example the case for stock values. The approach proposed here is inspired from Lengweiler's model, and it is based on an English auction with multiple items, private evaluations and variable requested quantities.

Consider a multi-item auction with one single vendor and a finite number $n$ of buyers or agents $A_{1}, \ldots, A_{n}$. A quantity $Q$ of identical items is available to be sold. Each buyer $A_{i}$ wishes to acquire a quantity $q_{i}$ of items with:

$$
\sum_{i=1}^{n} q_{i}>Q
$$

The amounts of money or budgets $V_{i}, i=1, \ldots, n$ of the $n$ buyers are extracted from a rectangular uniform distribution $F(V)$ on the interval $\left[V_{\min }, V_{\max }\right]$ where

$$
V_{\max }-V_{\min }>1
$$

This defines a model of private, independent valuations. The choice of a rectangular uniform distribution is a simplification of the more complex and realistic model. Given that $\mathrm{F}$ is rectangular and uniform, the following holds

$$
F\left(V_{i}\right)=\frac{1}{V_{\max }-V_{\min }}
$$

Because the items are identical, each buyer $A_{i}$ allows the same amount of money $v_{i}$ for all the items it wants to acquire such that

$$
V_{i}=\left(v_{i} \times q_{i}\right)
$$

The participants in the auction submit their offers as if they would desire to acquire just one single item. Their respective desired quantities $q_{i}$ are unknown to the vendor. Let $b_{i}$ the function of submission offers describing the auction strategy of buyer $A_{i}$ depending on its budget $V_{i}$ and the desired quantity $q_{i}$ of the item $i$ :

$$
b_{i}=b\left(V_{i}, q_{i}\right), i=1, \ldots, n
$$


Note that the buyer may decide to decrease the desired quantity during an auction in order to increase his possible bid of the item $i$ according to

$$
v_{i}^{\prime}=\frac{v_{i}}{q_{i}^{\prime}}
$$

where $v_{i}^{\prime}$ is the new amount of money allowed to an item by buyer $A_{i}$, and $q_{i}^{\prime}$ the new quantity desired with $q_{i}^{\prime}<q_{i}$.

Suppose for example that buyer $A_{i}$ has a global evaluation $V_{i}=100$ for the desired items. If this buyer asks for a quantity of items $q_{i}=10$, the amount of money he shall allow to each item would be:

$$
v_{i}=\frac{V_{i}}{q_{i}}=\frac{100}{10}=10
$$

If the buyer decides to decrease the quantity asked for to $q_{i}^{\prime}=5$ items, the the amount of money $v_{i}$ allocated to each item is calculated as follows:

$$
v_{i}^{\prime}=\frac{V_{i}}{q_{i}^{\prime}}=\frac{100}{5}=20
$$

At the end of the auction, buyer $A_{i}$ receives $\bar{q}_{i}$ items such that:

$$
\begin{array}{ll}
\bar{q}_{i}=q_{i} & \text { if } Q-\sum_{j: b_{j}>b_{i}} q_{j} \geq q_{i} \\
\bar{q}_{i}=Q-\sum_{b_{j}>b_{i}} q_{j} & \text { if } \quad 0<Q-\sum_{j: b_{j}>b_{i}} q_{j}<q_{i} \\
\bar{q}_{i}=0 & \text { if } Q-\sum_{j: b_{j}>b_{i}} q_{j} \leq 0
\end{array}
$$

Indeed, the quantity $\bar{q}_{i}$ obtained by buyer $A_{i}$ depends on the demands of the other buyers $A_{j}$ having submitted offers $b_{j}$ superior to his offer $b_{i}$. The quantities of those buyers are thus

$$
\sum_{j: b_{j}>b_{i}} q_{j}
$$

The last winning buyer $A_{i}$ may thus have his demand partially satisfied by the remaining quantity not sold to the others. For example, suppose that 10 items are for sale. The best offer for 8 of the items it desires is 15 . The second best offer is 10 for 5 items. The first buyer will receive the 8 items it asked for, while the second buyer will only receive $10-8=2$ items.

The winning buyers pay the amount of their bids multiplied by the quantity obtained: $b_{i} \times \bar{q}_{i}$. Their respective gains are:

$$
U_{i}=\left(\bar{v}_{i}-b_{i}\right) \times \bar{q}_{i}=V_{i}-b_{i} \bar{q}_{i}
$$

If a buyer doesn't make any bid, or he lost the auction, his gain is:

$$
U_{i}=0
$$

If the budgets allowed for the items to buy in the previous example are: 18 for the first winning buyer $A_{1}$ and 14 for the second one $A_{2}$, then, their respective gains should be: 


$$
\begin{gathered}
A_{1}: U_{1}=(18-15) \times 8=24 \\
A_{2}: U_{2}=(14-10) \times 2=8
\end{gathered}
$$

The function of gain $U_{i}$ is called the utility of buyer $A_{i}$. Each buyer $A_{i}$ tries to maximize its utility $U_{i}$.

\section{Strategy and equilibrium}

Every participant in the auction tries to win as if it were a simple English auction. Because a participant does not know which are the quantities asked for by the other participants, it may happen that his bid will be out-done by other buyers. It is thus faced with the risk that the demanded quantity $q_{i}$ will be entirely allocated to another buyer offering a higher price. The buyer is always faced with the dilemma where he wants to minimize his bid $b_{i}$ to maximize his gains, but where on the other hand it must take care that his bid $b_{i}$ has the best chances to win. A winner's course strategy taking into account these two contradicting constraint must therefor be defined.

Assume a buyer $A_{i}$ submits an offer $b_{i}$. For this bid to win, it is necessary that all the other $n-1$ bidders submit inferior offers with regard to $b_{i}$. The probability that any offer $b_{j}$ is inferior to the offer $b_{i}$ knowing that $A_{i}$ demands the quantity $q_{i}$ is:

$$
\begin{gathered}
P\left(b_{j}<b_{i} \mid q_{i}\right)=\int_{V_{\min }}^{q_{i} b_{i}} F(V) d V \\
\text { with } F(x)=\frac{1}{V_{\max }-V_{\min }}
\end{gathered}
$$

resulting in:

$$
P\left(b_{j}<b_{i} \mid q_{i}\right)=\frac{q_{i} b_{i}-V_{\min }}{V_{\max }-V_{\min }}
$$

The probability that all offers of the other $n-1$ buyers are inferior to $b_{i}$ is thus:

$$
\prod_{1}^{n-1} \frac{q_{i} b_{i}-V_{\min }}{V_{\max }-V_{\min }}=\left[\frac{q_{i} b_{i}-V_{\min }}{V_{\max }-V_{\min }}\right]^{n-1}
$$

All the buyers $A_{i}$ try to optimize their winning course by maximizing the probability to win the auction. The buyer therefore maximizes the following expression:

$$
X_{i}=\left(V_{i}-q_{i} b_{i}\right)\left[\frac{q_{i} b_{i}-V_{\min }}{V_{\max }-V_{\min }}\right]^{n-1}
$$

The following expression is now resolved:

$$
\partial X_{i} / \partial b_{i}=0
$$

This results in 


$$
-q_{i}\left(q_{i} b_{i}-V_{\min }\right)^{n-1}+\left(V_{i}-q_{i} b_{i}\right)(n-1) q_{i}\left(q_{i} b_{i}-V_{\min }\right)^{n-2}=0
$$

which yields after factorisation in

$$
q_{i}\left(q_{i} b_{i}-V_{\min }\right)^{n-2}\left[-\left(q_{i} b_{i}-V_{\min }\right)+\left(V_{i}-q_{i} b_{i}\right) \cdot(n-1)\right]=0
$$

Keeping only the solutions which maximize $\prod_{i}$ :

$$
\left(q_{i} b_{i}-V_{\min }\right)+\left(q_{i} b_{i}-V_{i}\right)(n-1)=0
$$

the result is

$$
\hat{b}_{i}=\frac{V_{\min }+(n-1) V_{i}}{n q_{i}}
$$

The expression $\hat{b}_{i}$ represents the optimal offer of buyer $A_{i}$ in the sense that it is the minimum offer maximizing the probability to win the auction, while assuming that the budgets of the other bidders are uniformly distributed. The set $\hat{b}_{i}, i=1, \ldots, n$ is the theoretical set of best bids. In section 6, we will compare these theoretical results with some of those extracted form the simulation of the model. Notice that buyer agents are not able to know their optimal bids because the $V_{\min }$ value is not a common information. The aim of the auction protocol is to make agents submit bids as close as possible to their optimal ones.

\section{Simulation}

The model presented in the previous section has been implemented as a simulation platform based on the multi-agent paradigm.

\subsection{Auctioning process}

A negotiation process may be represented as a finite state diagram. Figure 2 shows the negotiation process of a simple English auction adopted as the multi-item auction protocol in the implementation.

The state Begin indicates the start of the auction and represents the initial state of the automaton. The buyers now begin to submit their offers. Each time a better offer is submitted by a buyer agent $A_{i}$, it is sent to the other participants $A_{j}$ to inform them about the best current offer. This process continues while looping on the Bidding state until the auction closes. Clearing the auction results either with an Agreement or an unsuccessful end of the auction in the Stop state.

\subsection{Vendor agent}

The vendor agent shown in figure 3 supervises the auction process in a central manner. Its behavior can basically be described as a loop between an active Wait state and the sending and receiving of messages from the buyers. The vendor agent engages the 


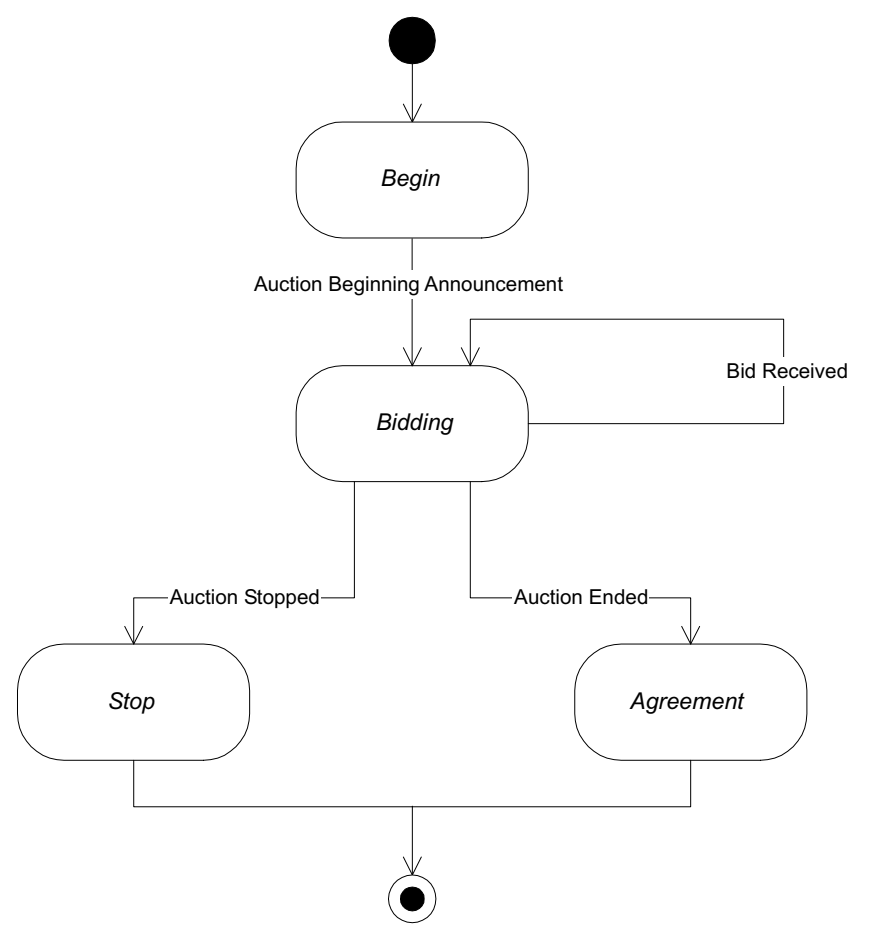

Figure 2: State diagram of an English auction 
auction by announcing its start to the buyers. It then expects offers in the Wait state. Each time the vendor receives an offer, it announces it to the buyers as the current best offer without, however, revealing the buyer's identity nor the quantity asked for. The vendor agent knows the number $n$ of buyers participating in the auction. If a buyer leaves the auction, it decrements the number $n$ and reintegrates the Wait state. When only one buyer is left, the vendor agent announces the end of the auction.

The vendor agent can be considered as a reactive agent which reacts to exterior stimuli, i.e. the messages arriving from the buyer agents $A_{i}$. It interacts with the environment by sending messages to the buyers as described above.

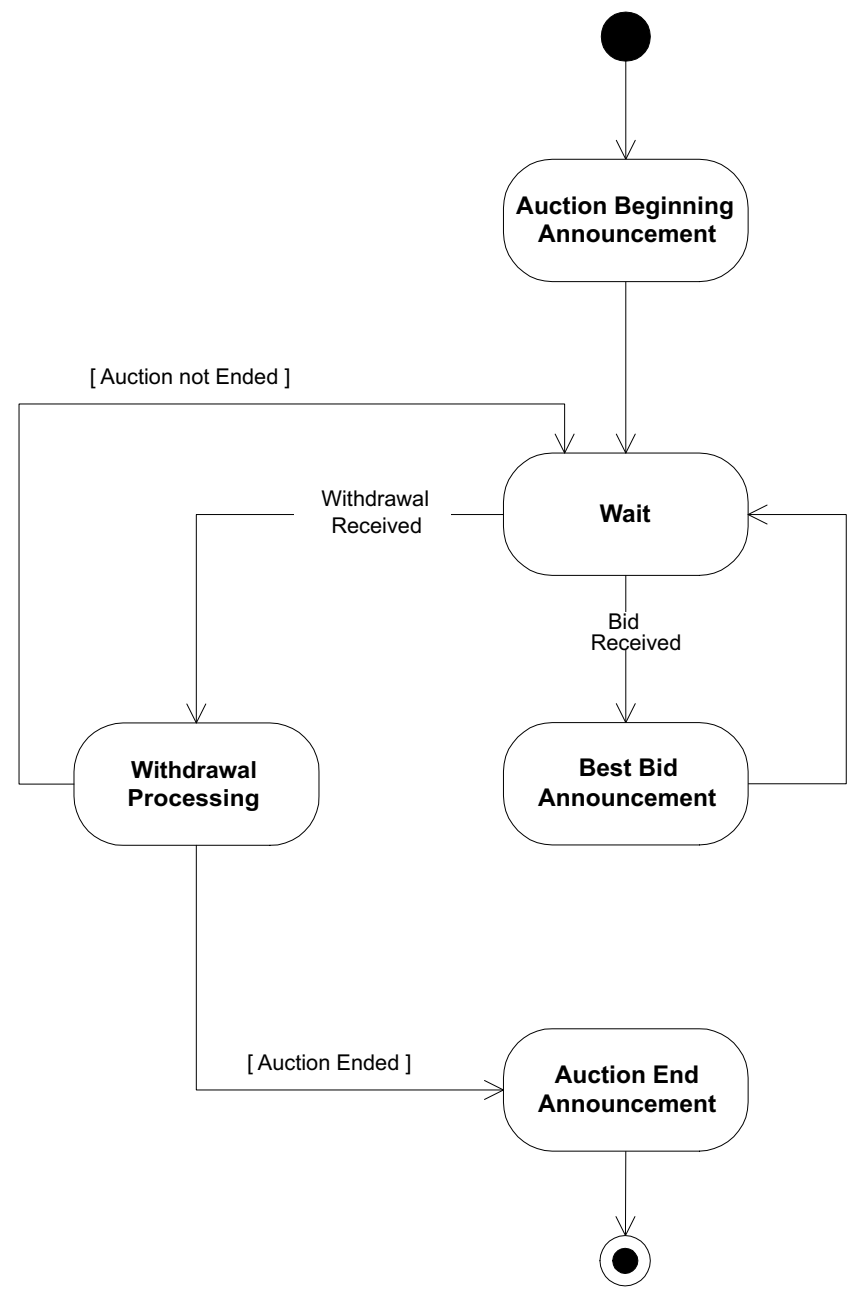

Figure 3: State diagram of the vendor agent. 


\subsection{Buyer agent}

The behavior of the buyer agent is defined by his winning course strategy as discussed in section 4. The strategy for maximizing the buyer's gain is fixed in advance.

\subsubsection{Enrichment strategy}

While bidding, the buyer agent must take a decision on: (1) the offer to submit and (2) the decrease of the quantity demanded. There are thus two parameters to be set for choosing the enrichment strategy: (1) how and when to place an offer, and (2) how and when to decrease the quantity asked for.

The enrichment strategy of the buyer agent is modelled with two linear functions, which represent a more or a less aggressive behavior:

1. price offered as a function of time, during the auction progress, as illustrated in figure 4.

2. quantity asked for as a function of time, during the auction progress as illustrated in figure 5 .

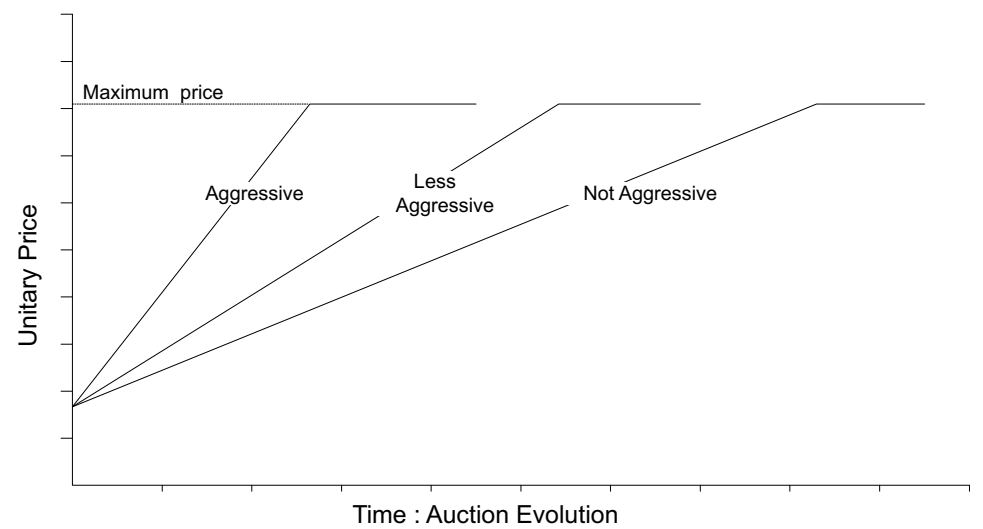

Figure 4: Price offered during the auction's progress.

\subsubsection{Behavior of the buyer agent}

When a buyer agent starts to participate in an auction it is in the state Waiting Time Determination (see figure 6) where it determines the time interval of inactivity according to its enrichment strategy. It then passes on to the Wait state. At the end of this waiting period, the agent verifies the current price in the Current Price Verification state. If his offer is still the winning one, i.e. no other buyer agent has submitted a superior offer during its time of inactivity, he determines his new waiting time according to his 


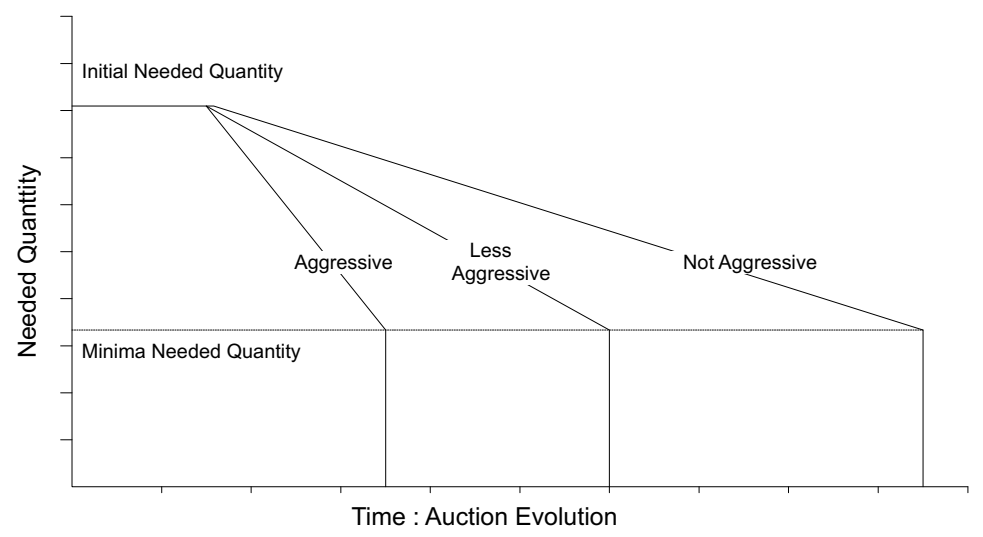

Figure 5: Quantity demanded during the auction's progress.

enrichment strategy . The buyer agent continues looping on the Waiting Time Determination and Wait states until another buyer has submitted a better offer. At this time, the buyer agent starts a process of enrichment in order to submit a superior offer and passes thus on to the state of Bid Determination. If it can submit a better offer, the buyer agent changes to the Bid Submission state and sends a message to the vendor agent with his price offer and the quantity desired.

In case the buyer cannot submit a better offer, he tries to decrease his quantity. In the state of Quantity Decrement, the buyer agent seeks to diminish the quantity asked for according to his strategy, i.e. more or less aggressively. As long as he cannot make a better offer, he continues to decrease the quantity. If the agent achieves his goal, it submits the new offer, otherwise it abandons the auction and passes to the state Withdrawal and Wait.

Finally, when the auction will be terminated, the buyer agent receives a signal from the vendor agent and then passes on to the state Clearing Auction. The winner will receive a message from the vendor indicating the price and quantity won. It has to be noted here, that there may be more than one winner, each acquiring a different quantity as illustrated in the example in section 3. The state diagram in figure 6 summarizes the behavior of the buyer agent.

\section{Empirical evaluation}

This section presents and discusses empirical results obtained by the simulation of the model described in this paper. Three different cases are evaluated.

\section{Case 1: Same needs and same budgets}

Suppose there are 10 items to sell and $n=5$ buyer agents. All the buyers $A_{1 \ldots 5}$ dispose of similar amounts of money to spend $\left(V_{i} \approx V_{\min } \approx V_{\max }, 1 \leq i \leq 5\right)$. The initial quantity each buyer $A_{i}$ asks for is equal to 10 items $\left(q_{i}=10,1 \leq i \leq 5\right)$, and the 


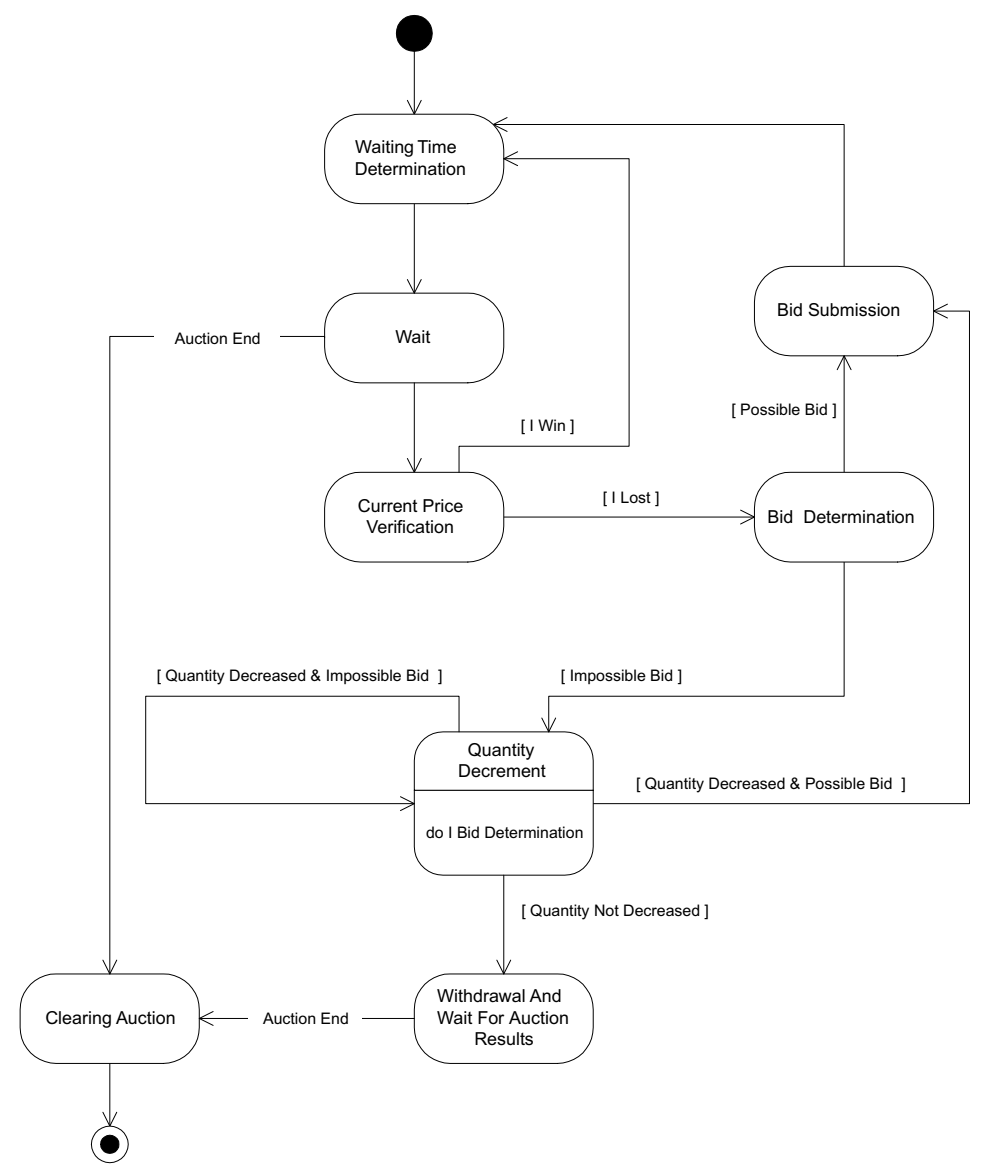

Figure 6: Behavior of the buyer agent. 
minimum quantity accepted by the vendor agent shall be 6 items. The strategies of the buyers are randomly generated. The minimum quantity requested by a buyer does not significantly influence the results of the experiment.

This scenario represents a case of aggressive competition because all the buyers show the same (or similar) needs for the quantities desired and the amounts of money available to buy the items are similar as well. One can thus expect that the buyers will heavily decrease their quantity demands in order to win the auction. The revenue of the vendor is in this case not affected by the number of buyer agents. Indeed, the following equation holds:

$$
\hat{b}_{i}=\frac{V+(n-1) V}{n q_{i}}=\frac{V}{q_{i}}=v_{i}
$$

The optimal offer for each buyer agent is therefore his own valuation $v_{i}$ of the item.

Figure 7 first shows the revenue of the vendor depending on the means the buyers dispose, i.e. the buyers' budgets, without any decrease of the requested quantities. Second, the figure presents the vendor's revenue in case the desired quantities are decremented down to a minimum of 6 items.

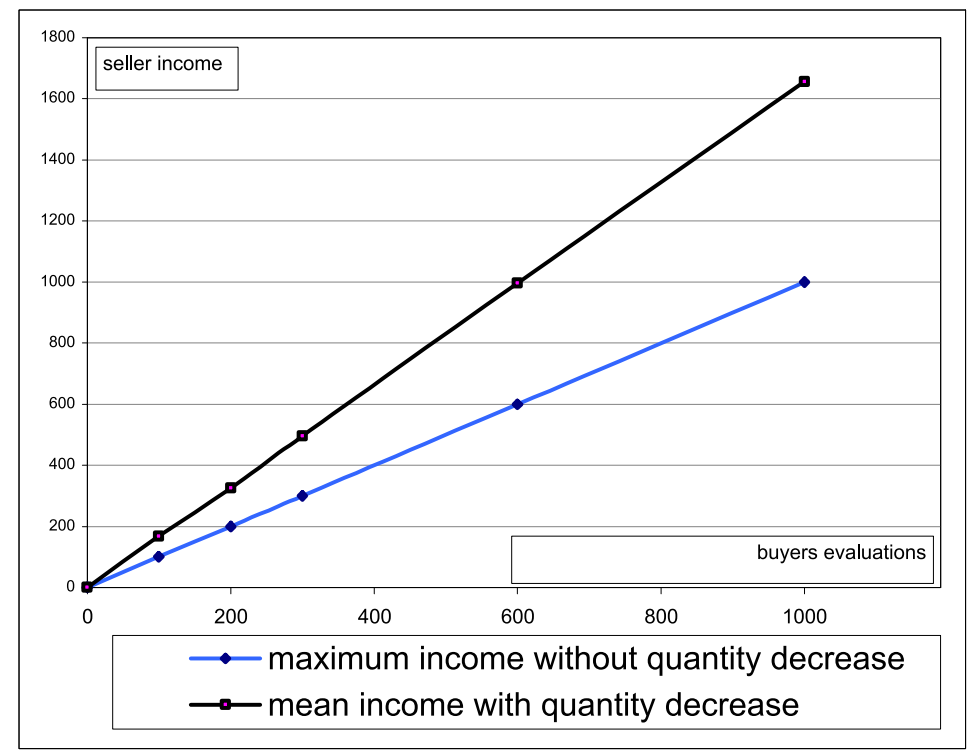

Figure 7: Vendor revenue in case of heavy competition.

\section{Case 2: Same needs but different budgets: influence of the number of buyer agents}

Suppose the same parameters as in Case 1 except that the buyer agents have different budgets, i.e. they dispose of different amounts of money to spend. The budgets of 
the 5 buyers are determined according to a uniform distribution with $V_{\min }=100$ and $V_{\max }=300$.

The competition is not as aggressive as in Case 1. Along the auction, the agents with smaller budgets will abandon. In the end only two agents will stay and compete to win the auction.

Figure 8 shows the influence of the number of buyer agents on the revenue of the vendor. The model presented in this paper allows to considerably increase the mean revenue of the vendor. In order to maximize his revenue, the vendor should attract a large number of buyers. In case there is no decrease in the quantity requested, the revenue of the vendor stabilized with 20 buyers and more. The revenue stabilisation occurs later with the possibility to decrement the desired quantity.

Figure 8 shows that this happens only with 40 and more buyers. This difference can be explained by the competition which is always more accentuated compared to a model where the requested quantities do not decrease. Another point is that our model gives much more income to the vendor in the case of a model without quantity decrease by the buyers. In the same time, the simulation shows that the curve of the mean income is close to the maximum theoretical income $r_{\max }$ which is calculated using the optimal bids $\hat{b}_{i}$ introduced in equation 16 :

$$
r_{\max }=\sum_{i=1}^{k-1} \hat{b_{i}} q_{i}+\hat{b_{k}}\left(Q-\sum_{i=1}^{k-1} q_{i}\right)
$$

\section{Case 3: Same needs but different budgets: influence of the minimal offer}

The parameters are the same as in Case 2 except that the number of buyer agents is fixed to 10. The vendor may define a minimal incremental value for an offer. While increasing this minimal incrementation value, the number of offers is decreased, which in turn minimizes the communications between the buyers and the vendor. The simulation experiments have shown that a large incrementation value results in a globally decreasing mean revenue for the vendor. Figure 9 presents this correlation. The curve representing this relation shows however, that there are certain incrementation values allowing better revenues than smaller ones. Indeed, the curve has a wave form with increasing period. For example, the minimal incrementation value of 10 generates superior revenues compared to the incrementation values of 8 and 9. This behavior depends on the function determining the budgets of the buyers. Given that $V_{\max }=300$ in the current example, the maximum offer a buyer with a budget of $V_{i}=300$ can make to obtain the 6 items (minimal number of requested items) will be 50 per item. If the minimal incrementation is set to 9 , the maximum offer per item will be 45 . On the other hand, if the minimal increment value is 10 , the maximum value of 50 to offer per item can be achieved. This explains the wave form of the curve in figure 9.

In the three cases discussed here, we noticed that the bidding strategies described in section 5.3.1 does not significantly influence the results. If fact, the strategies have great influence on the duration of the auction: while non aggressive buyers will take their time before submitting a bid, aggressive ones will do it faster. 


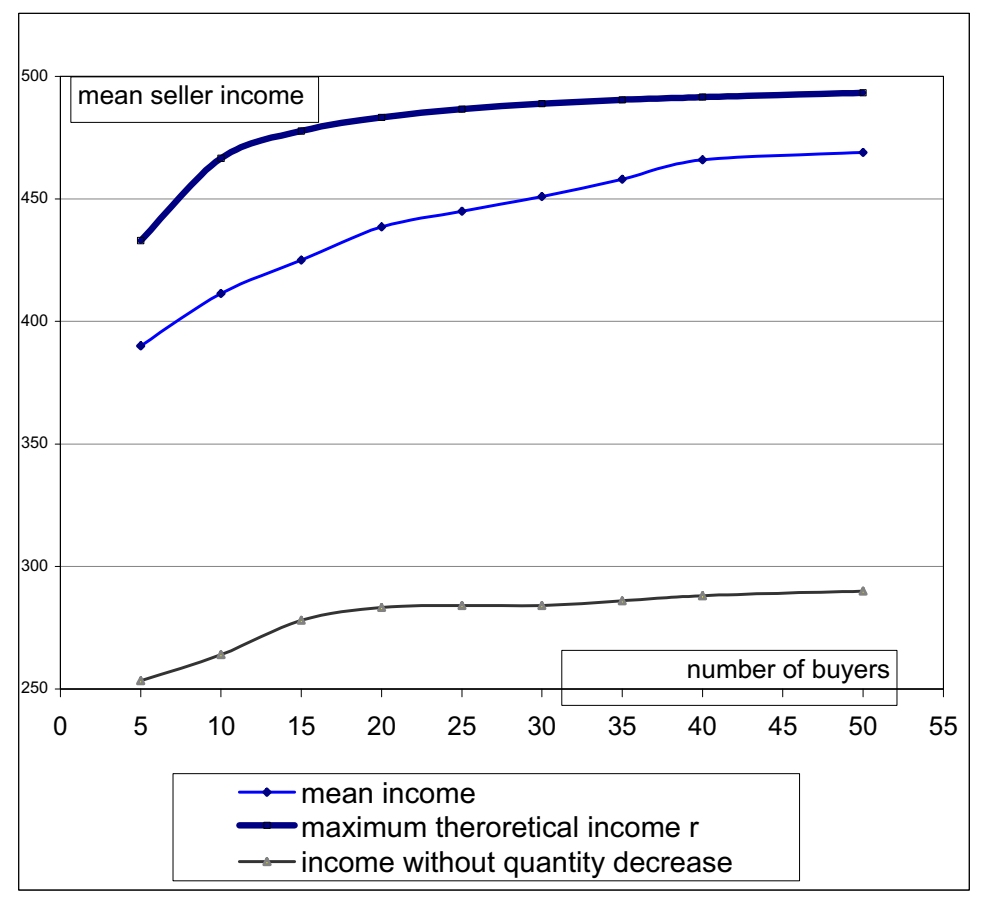

Figure 8: Vendor revenue in relation to the number of buyers. 


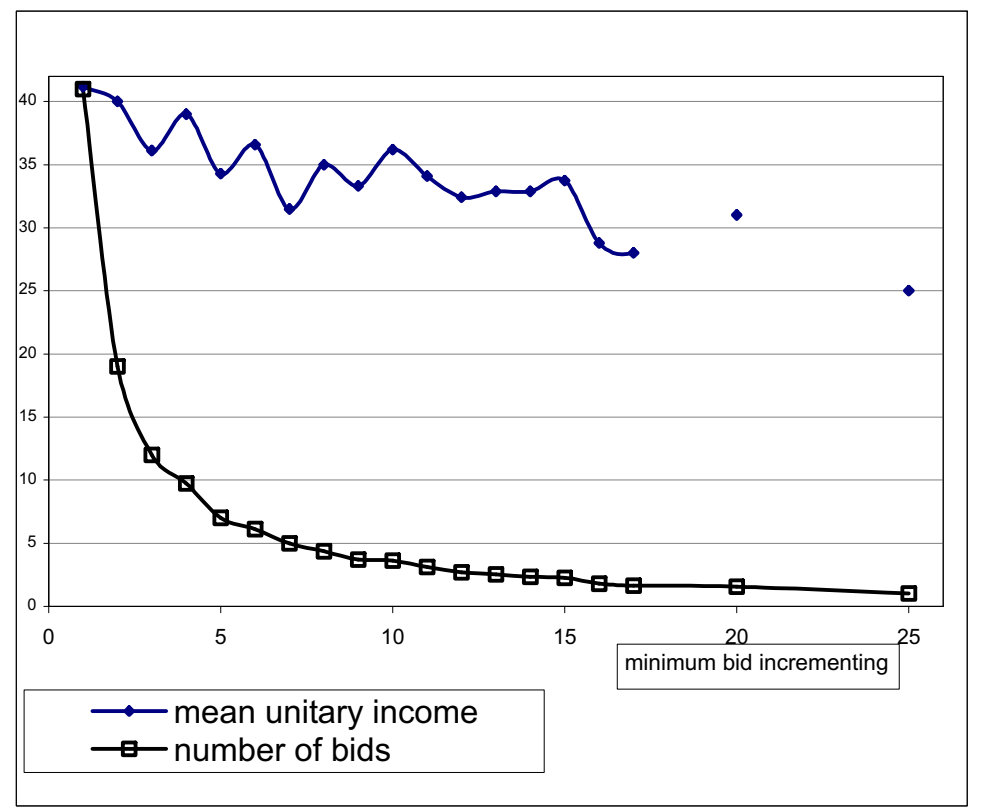

Figure 9: Vendor revenue and number of bids in relation to the minimal bid increment value.

\section{Conclusion}

In this paper we discussed the multi-agent paradigm and its application to multi-item auctions. We proposed a formal model for auction based automatic negotiations. This model has been implemented using multi-agent systems and was tested and evaluated with simulation experiments. Recently, much work on multi-item auctions have addressed the combinatorial issue that allows bids on combinations of items as opposed to only single items. These approaches suppose however, two simplifying conditions: the quantity of items to sell is fixed as well as the quantities requested by the buyers. These two hypothesis do not meet the requirements of many situations where auctions are used. In some auctions, it is more desirable to not fix the available quantity. It this way, quantities can change during the auction, as it is for example the case for stock values. The approach that we have proposed here, follows this road. To achieve it, we presented a model based on an English auction with multiple items with private valuations and variable quantities requested. With such a model, we succeed in characterizing:

1. How a large incrementation value results in a globally decreasing mean revenue for the vendor;

2. How an augmentation of the incrementation value (by the vendor) decreases the number of offers, which in turn minimizes the communications between buyers and the vendor; 
3. How the vendor's revenue stabilizes with 20 buyers and more in the case where there is no decrease in the quantity requested, and with 40 buyers or more when a decrease of the requested quantity is considered;

4. How the vendor's revenue increases with large quantity variations in the quantities requested;

5. Finally, the implementation using multi-agent systems showed the suitability of this paradigm for this application.

In conclusion, we believe that our model for automatic negotiations is a suitable approach to enhance the capabilities of auction systems while imposing less constraints. In future work, we will investigate other enrichment strategies where agents may try to be second or third highest in the end of the auction. The buyer will take the risk of loosing the auction, but if he wins, he will pay less than the first winner. Also, we are thinking about experiments with other types of auctions. Given the first experimental results of this paper we expect to successfully demonstrate the power of this model with such variations as well.

\section{ACKNOWLEDGEMENTS}

This work was partially supported by the Canadian Natural Sciences and Engineering Research Council (NSERC).

\section{References}

[1] G. Weiss, Multiagent Systems, MIT Press, 1999, Ch. Prologue, pp. 1-23.

[2] W. Vickrey, Counter speculation, auctions, and competitive sealed tenders, Journal of Finance 16 (1) (1961) 8-37.

[3] M. Osborne, R. Rubistein, A Course in Game Theory, MIT Press, 1994.

[4] E. Rasmussen, Games and Information, Blackwell Oxford, 1994, second Edition.

[5] P. Klemperer, Auction theory : A guide to the literature, Journal of Economic Surveys 13 (3).

[6] Federal communications commission : All about auctions, FCC Report (September 1999).

[7] eBay, http://www.ebay.com/.

[8] Moai, http://www.moai.com/.

[9] Agorics Inc., Going Going Gone! A Survey of Auction Types, http://www.agorics.com/new.html.

[10] Market Design Inc., http://www.agorics.com/new.html. 
[11] P. Milgrom, Auction Theory for Privatization, Cambridge University Press, 1998.

[12] P. Wurman, Market structure and multidimensional auction design for computational economies, Ph.D. thesis, University of Michigan (1999).

[13] J. Rosenschein, G. Zlotkin, Rules of Encounter : Designing Conventions for Automated Negotiation Among Computers, Artificial Intelligence, MIT Press, 1994.

[14] T. Sandholm, Limitations of the Vickery auction in computational multiagent systems, in: Proceedings of the Second International Conference on Multiagent Systems (ICMAS-96), Kyoto, Japan, 1996.

[15] Forrester Research, Dynamic trade research brief, http://www.forrester.com/ER/Research/Brief/0,1317,1481,FF.html.

[16] S. Klein, Introduction to electronic auctions, International Journal of Electronic Markets 7 (4).

[17] E. Turban, Auctions and bidding on the Internet : An assessement, International Journal of Electronic Markets 7 (4).

[18] M. Benyoucef, K. Keller, S. Lamoureux, J. Robert, Towards a generic enegotiation platform, in: Sixth Int. Conference on Re-Technologies for Information Systems, Austrian Computer Society, Zurich, Switzerland, 2000, pp. 95-109.

[19] P. Maes, R. Guttman, A. Moukas, Agents that buy and sell: Transforming commerce as we know it, Communications of the ACM 42 (3).

[20] G. Kersten, S. Noronha, J. Teich, Are all e-commerce negotiations auctions?, in: COOP'2000 : 4th International Conference on the Design of Cooperative Systems, Sophia-Antipolis, France, 2000.

[21] A. Chavez, P. Maes, KABASH: An agent marketplace for buying and selling goods, in: 1st Int. Conference on Electronic Commerce, IECE'98, Soeul, Korea, 1998.

[22] D. Parker, L. Ungar, D. Forster, Agent Mediated Electronic Commerce, Springer, 1999, Ch. Accounting for Cognitive Costs in On-line Auction Design, pp. 25-40.

[23] J. Hu, D. Reeves, H. Wong, Agent service for online auctions, in: Proceedings of the AAAI-99 Workshop on AI for Electronic Commerce, AAAI Press, 1999.

[24] M. Côté, Une architecture multiagent et son application aux services financiers, Master's thesis, Département d'informatique, Université Laval (1999).

[25] J. Teich, H. Wallenius, J. Wallenius, Multiple issue auction and market algorithm for the world wide web, Tech. Rep. IR-98-109/December, International Institute for Applied Systems Analysis, Austria (December 1998).

[26] R. Guttman, P. Maes, Cooperative vs. competitive multi-agent negotiations in retail electronic commerce, in: Proceedings of the Second International Workshop on Cooperative Information Agents (CIA'98), Paris, France, 1998. 
[27] W. Lomuscio, N. Jennings, Agent-Mediated Electronic Commerce, Springer, 2000, Ch. A Classification Scheme for Negotiation in Electronic Commerce.

[28] M. Benyoucef, K. Keller, An evaluation of formalisms for negotiations in ecommerce, in: P. Kropf, et alt. (Eds.), Distributed Communities on the WEB, Vol. 1830 of LNCS, Springer, 2000, pp. 45-54.

[29] D. Ferguson, C. Nikolaou, J. Sairamesh, Y. Yemini, Market Based Control of Distributed Systems, scott clearwater Edition, World Scientific Press, 1996, Ch. Economic Models for Allocating Resources in Computer Systems.

[30] OMG, Negotiation facility final revised submission, Technical report, http://www.oms.net (Mar. 1999).

[31] T. Sandholm, Multiagent Systems A Modern Approach to Distributed Artificial Intelligence, MIT Press, 1999, Ch. Distributed Rational Decision Making.

[32] T. Sandholm, Automated negotiation, Communications of the ACM 42 (3) (1999) 84-85.

[33] M. Kumar, S. Feldmann, Internet auctions, Tech. rep., IBM Institute for Advanced Commerce, Yorktown Heights, NY (1998).

[34] Y. Lengwiler, The multiple unit auction with variable supply, Economic Theory Journal 14 (2) (1999) 373-392. 